\title{
Into the Light: Effects of the Presence of Cleaning Staff on Customer Experience
}

Martijn C. Vos ${ }^{a, b, c, *}$, Jessica Saurenc, Olaf Knoop ${ }^{d}$, Mirjam Galetzka ${ }^{a}$, Mark P. Mobach ${ }^{b, e}$, Ad T.H. Pruyn ${ }^{\mathrm{a}}$

a University of Twente, PO Box 217, $7500 \mathrm{AE}$, Enschede, the Netherlands

${ }^{\mathrm{b}}$ Hanze University of Applied Sciences, PO Box 70030, 9704 AA Groningen, the Netherlands

c Netherlands Railways, PO Box 2372, 3500 ER Utrecht, the Netherlands

d Hago Rail Services, PO Box 354, 1200 AJ Hilversum, the Netherlands

e The Hague University of Applied Sciences, PO Box 13336, 2521 EN The Hague, the Netherlands

* Corresponding author

E-mail addresses: m.c.vos@utwente.nl (Martijn C. Vos), jessica.sauren@ns.nl (Jessica Sauren), Olaf.Knoop@hago.nl (Olaf Knoop), m.galetzka@utwente.nl (Mirjam Galetzka), m.p.mobach@pl.hanze.nl (Mark P. Mobach), a.t.h.pruyn@utwente.nl (Ad Pruyn). 


\section{Abstract}

Purpose: Day-time cleaning is becoming increasingly popular in (public) service environments. It is however unknown how the presence of cleaning staff in the service environment affects perceptions and satisfaction of end-users. An experimental field study was conducted during the train journey to determine how the presence of cleaning staff affects perceptions and satisfaction of train passengers.

Design/methodology/approach: Two experimental field studies were performed. Data for the first study were collected on the trajectory between the train station of Assen and the station of Groningen $(N=506)$ in the northern part of the Netherlands. Data for the second study were collected on the trajectory between train station "Amsterdam Amstel" and train station "Utrecht Centraal" $(N=1,113)$ in the central part of the Netherlands. In the experimental condition two cleaners collected waste and performed minor cleaning activities (i.e., empty trash bins, cleaning doors, and tables) during the journey. After the first study, cleaners received hospitality training and corporate uniforms.

Findings: The presence of cleaning staff positively influenced train passengers' perceptions and satisfaction. Effects were stronger in the second study, after the second consecutive intervention (i.e., hospitality training, corporate uniforms). In both studies, the presence of cleaners positively influenced passengers' perceptions of staff, cleanliness, and comfort. The perception of atmosphere was only significant after the intervention.

Practical implications: The findings of this study allow in-house and corporate facility managers to better understand the possible effects of the presence of their cleaning staff on end-user perceptions and satisfaction.

Originality/value: The study's value lies in its human centred approach by demonstrating the importance of day-time cleaning. This area of research has been largely neglected in the field of facilities and (public) services management research.

Keywords: cleanliness, hospitality, corporate uniform, train journey, day-time cleaning, field study

Paper type - Research paper 


\section{Introduction}

Cleanliness is one of the key drivers of overall customer satisfaction (Wakefield \&Blodgett, 1996, van Lierop et al., 2017). Very often a distinction is made between actual cleanliness and subjective perceptions of cleanliness (in the following: end-user perceptions of cleanliness). Knowledge and standards on how to manage actual cleanliness are widely available in literature (e.g., Van Ryzin et al., 2008, Johanne Klungseth, 2014) and practice (e.g., the Netherlands: NEN 2075, international: ISO 9001). Knowledge on how to manage and positively influence end-user perceptions of cleanliness is limited in current literature (Whitehead et al., 2007, Vos et al., in press). The following variables were identified as variables that positively influence end-user perceptions of cleanliness: actual cleanliness (Van Ryzin et al., 2008), scent (Whatley et al., 2012), deterioration (Wells \& Daunt, 2015), shininess (Broeders et al., 2011), architectural order (Da Luz Reis \& Dias Lay, 2009), and the presence of cleaning-staff in a healthcare setting (Whatley et al., 2012, Whitehead et al., 2007).

Interestingly, research on cleaning staff or cleaning in general is scarce (Klungseth \& Olsson, 2013). Only a few researchers have investigated cleaning work from the perspective of the cleaning staff and/or end-users (Agular, 2001, Hood, 1988). We have taken a step toward a more human-centred approach in facilities management research by presenting a study in which we have taken cleaning-staff out of the shadows, into the light. Currently, most cleaners in this sector work during night time without having direct contact with end-users. As part of this study, these workers are taken "out of the shadows, into the light" by introducing daytime work. Their physiques, uniforms, and work are visible and exposed to end-users. The main aim of the two studies that are presented in this paper is to evaluate the effects of the presence and behaviour of cleaning staff in trains on the experience of train passengers. The following research question will be addressed: "to what extent does the presence of cleaning staff influence the experience of train passengers?". 


\section{Theoretical framework}

First, we will address the role of (cleaning) staff in the experience of the service environment. Secondly, we will discuss current literature on the effects of the visibility of cleaning staff in the service environment.

\section{Factors influencing customer experience}

The customer experiences that companies create, matter more than ever (Pine and Gilmore, 1998). Customer experience was defined as a multidimensional construct that is holistic in nature and involves the customers' cognitive, affective, emotional, social, and physical responses to the service provider (Lemon \& Verhoef, 2016). Design, ambient, and social factors are considered to be important predictors of customer experience (e.g., Bitner, 1992, Baker et al., 2002, Baker, 1987). (1) Design factors can be divided into two dimensions, a functional dimension and an aesthetic dimension. The functional dimension comprises the layout and comfort of the service environment, the aesthetic dimension includes architecture, colour, and materials. In general, design factors are more visual and tangible in nature compared to ambient factors which tend to affect nonvisual senses (Baker et al., 2002). (2) Ambient factors are considered to be background conditions that influence the subconscious experience of end-users. Examples of such factors are climate, lighting, acoustics, scent, and music. In most cases, end-users will only be aware of these factors when they are absent or exist at an unpleasant level (Baker, 1987). The experience of the service environment is influenced by (3) social factors as well. Very often, a distinction is made between the presence of other customers and service personnel. In general, the number, appearance, and behaviour of other customers is believed to influence the end-user experience of the environment (Baker, 1987). There are often multiple end-users in a service environment simultaneously, and the experience of each end-user can impact that of others (Verhoef et al., 2009). Eye-contact, one's general appearance, loud voice may, for example, be perceived as disturbing or even threatening (e.g., Aronoff et al., 1992, Verhoef et al., 2009). The interaction between customers 
and service personnel (i.e., the service encounter) is considered to be a crucial factor in the service delivery process which influences customer experience. In many cases, the service encounter itself is considered as the service from the end-user point of view (Bitner et al., 1990, Vilnai-Yavetz \& Rafaeli, 2011). Service personnel is able to communicate a firm's ideals and attributes through the service encounter. By doing so, service personnel is able to positively (or negatively) influence customer satisfaction and perceptions of service quality (Baker et al., 1994). To conclude, customer experience is defined as a set of variables that can be influenced by the quality of design, ambient, and/or social factors.

\section{Presence of cleaning staff}

In general, most research focusses on the presence of employees in a retail environment who are part of the service encounter (e.g., cashiers, sales people). Research on the presence of cleaning staff or cleaning in general could be considered as underexposed in current facilities management (FM) literature (Klungseth \& Olsson, 2013). A literature search in the databases of two major FM journals (i.e., Facilities, Journal of Facilities Management) yielded only a handful of relevant studies on cleaning and the presence of cleaning staff. Most of these studies are about the managerial side of cleaning by focussing on the make or buy decision for cleaning services (e.g., Klungseth et al., 2016, Houston \& Youngs, 1996, Gbadegesin \& Babatunde, 2015), end-user satisfaction with cleaning services (e.g., Hui et al., 2013, Hui \& Zheng, 2010), and cost management (e.g., Bywater, 1990). The qualitative studies of Whitehead et al. (2007) and Whatley et al. (2012) are to the knowledge of the authors the only studies evaluating the effect of cleaning staff on end-user perceptions. In both studies, the presence of cleaning staff and more specifically the appearance, behaviour, and attitude of cleaning staff were identified as 'social cues' that positively influence perceptions of cleanliness. Both studies were however performed in a health-care setting, research on the presence of cleaning staff in the (public) service environment lacks. As noted, the interaction between cleaners and customers is considered to be one of the main advantages of increased presence of cleaning staff. Previous research stated that the experience of employees in the 
service environment is correlated with the experience they create for their customers (e.g., Parish et al., 2008, Schneider et al., 2005). Besides the positive implications of the presence of cleaning staff for end-users, research indicates that cleaning staff may benefit as well. Whereas cleaners who work during the night might feel ignored and experience the dirty-work stigma (Van Vlijmen, 2017, Ashforth \& Kreiner, 1999), day-time cleaners might benefit from the feeling of being part of the primary service delivery process. To conclude, research in facilities management on the effects of the presence of cleaning staff on end-user perceptions is limited. The qualitative work available (Whitehead et al., 2007, Whatley et al., 2012) demonstrated that the presence of cleaning staff in the service environment might be beneficial for end-users.

\section{Concluding: from theory to practice}

The current study evaluates the effect of the presence and behaviour of cleaning staff on the experience of train passengers. Van Hagen and Sauren (2014) operationalised the train passenger experience by developing a measurement instrument that includes the three dimensions of customer experience (i.e., design, ambient, \& social factors). Based on this distinction, the train passenger experience was defined as following:

1. Design factors: perception of comfort;

2. Ambient factors: perception of atmosphere and cleanliness;

3. Social factors: perception of staff and other customers.

In addition, the perception of time was included as well since (the subjective experience of) time is an important aspect for passengers who undertake a train journey (Van Hagen et al., 2014). Previous research (Whatley et al., 2012, Whitehead et al., 2007) demonstrated that the presence of cleaning staff may positively influence perceptions of cleanliness. Our expectation is that the presence of cleaning staff positively influences the perception of staff, cleanliness, comfort, trip speed, atmosphere, and the general satisfaction of passengers (see Figure 1). We expect that the presence of cleaning staff is perceived as a social cue which implies the presence of other positive traits in the environment. This phenomenon can be interpreted 
following the "halo effect" (Eagly et al., 1991). The "halo effect" suggests that people tend to assume that one positive trait (i.e., presence of friendly and helpful cleaning staff) implies the presence of other positive traits (e.g., cleaner environment, comfortable seating, shorter travel time). Two field experiments were performed to determine if the presence of cleaning staff influenced perceptions and satisfaction of passengers. The first study took place in trains of Netherlands Railways on the trajectory between the train stations of Assen and Groningen in July 2015 . The second study was carried out in similar trains but on the trajectory between the central train station of Utrecht and train station "Amsterdam Amstel" in September and October 2015. In the both studies, (male and female) cleaners were instructed to empty the bins and perform minor cleaning activities. After the first study, the cleaners received a hospitality training and corporate uniforms (see Figure 1 and Figure 2 for difference). Our expectation is that the effects of the presence of cleaners will be even stronger in the second study due to the intervention (i.e., hospitality training, corporate uniforms).

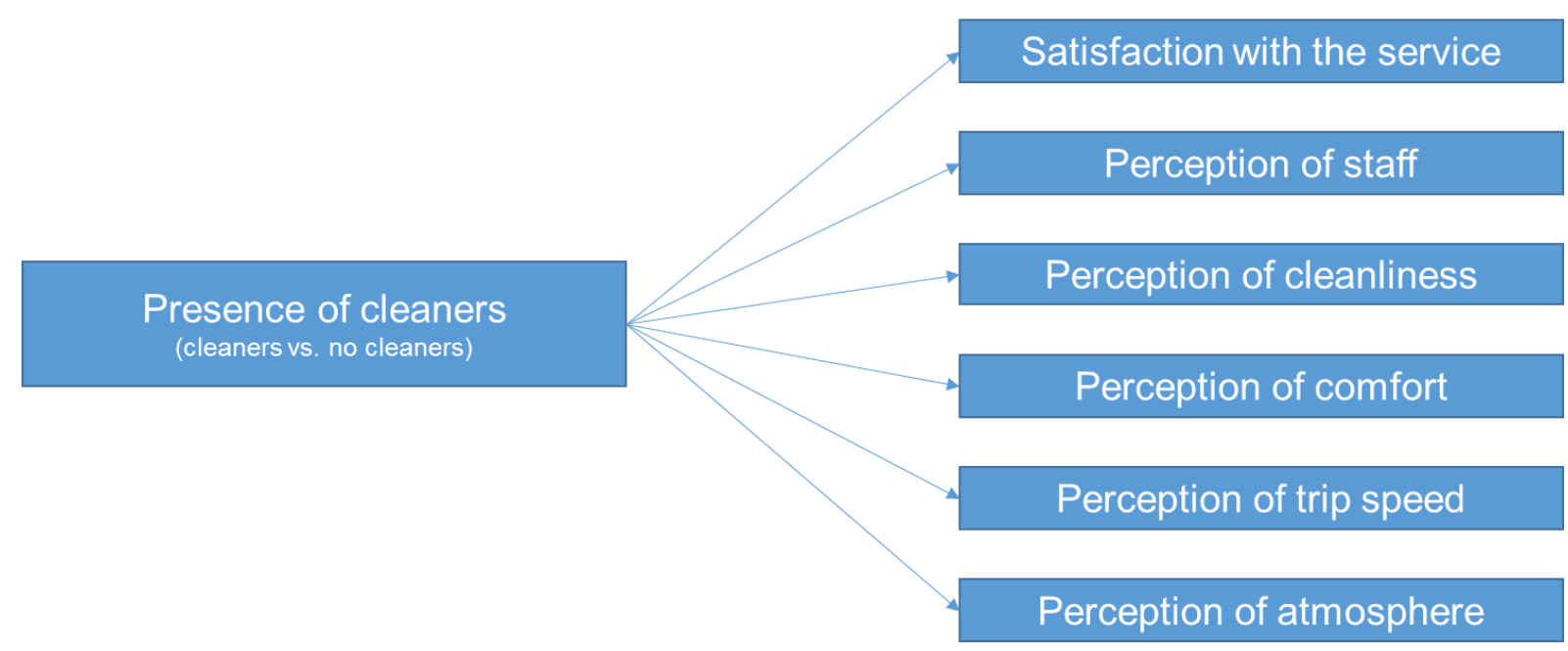

Figure 1. Overview key constructs

\section{Method}

\section{Procedure}

Data for the two studies were collected during off-peak hours (i.e., 9 AM- 16 PM). The distance and travel time between Assen-Groningen (35 kilometres, 18 minutes) and Utrecht-Amsterdam 
(40 kilometres, 21 minutes) is comparable. Cleaners participated voluntarily. The studies consisted of an experimental and a control condition. In the experimental condition of both studies two gloved cleaners, dressed in a yellow safety vest in study 1 (Figure 2) or corporate uniform in study 2 (Figure 3), collected waste and performed minor cleaning activities during the journey. More specifically, cleaners were instructed to empty the bins, clean the glass doors of the train compartments, and if possible, clean the non-foldable tables. After the first study, cleaners received hospitality training in which they were instructed to greet the passengers when entering the train, provided travel information if needed, and learned how to interact with different types of passengers through roleplay with a professional actor. Cleaners were, for example, instructed to skip passengers who were actively engaged in working activities and interact with passengers who were open to it. In the control condition, no cleaning staff was present. Data of the experimental and control conditions were gathered on the same days. Data for the first study were collected in the summer of 2015 (July), data for the second study were collected in the fall of 2015 (September, October). To reduce bias, data for the experimental and control condition were collected in the morning (9 AM-12:30 PM) as well as in the afternoon (12:30 PM - 16 PM).

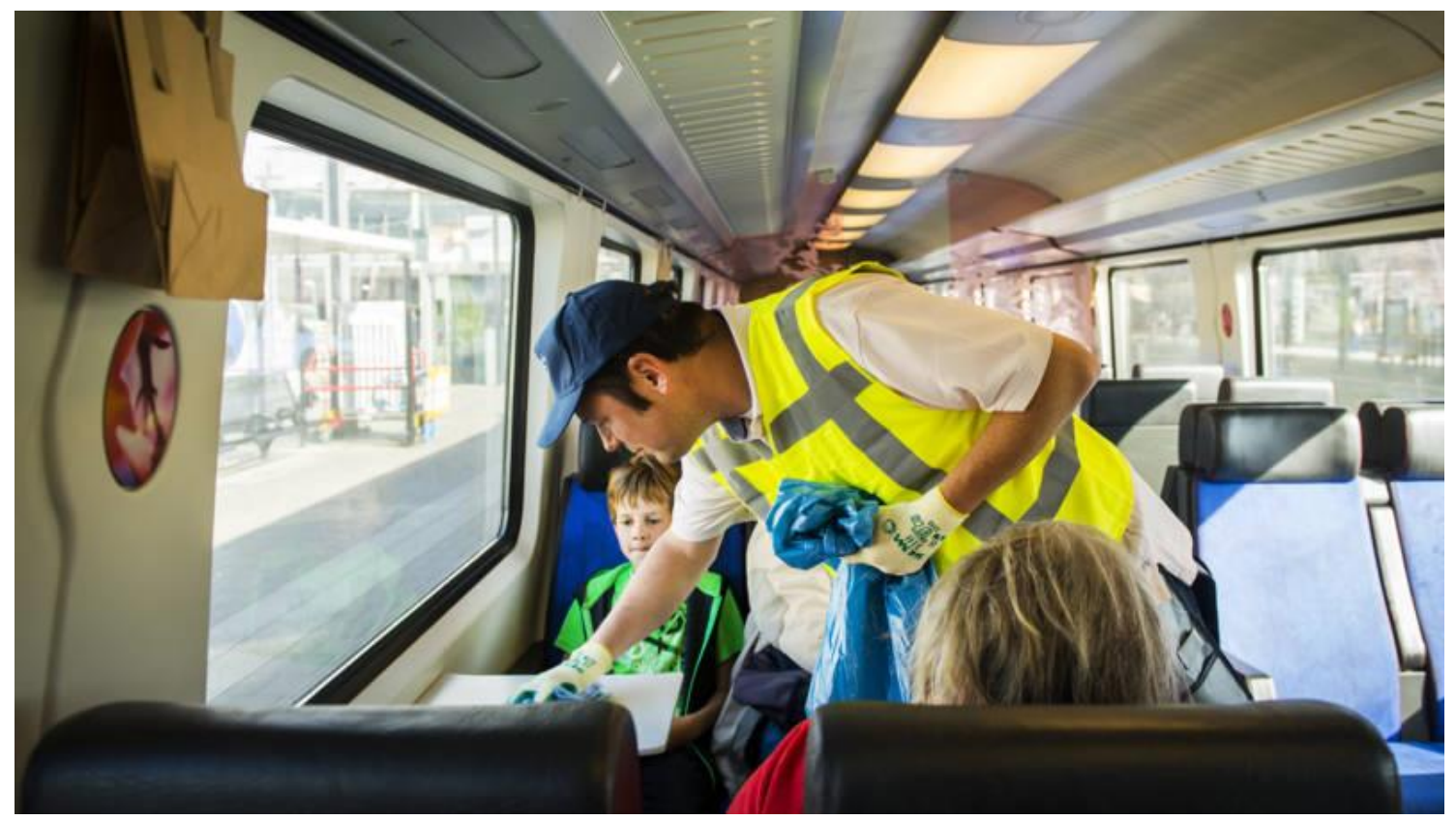

Figure 2. A cleaner who participated in the first study. 


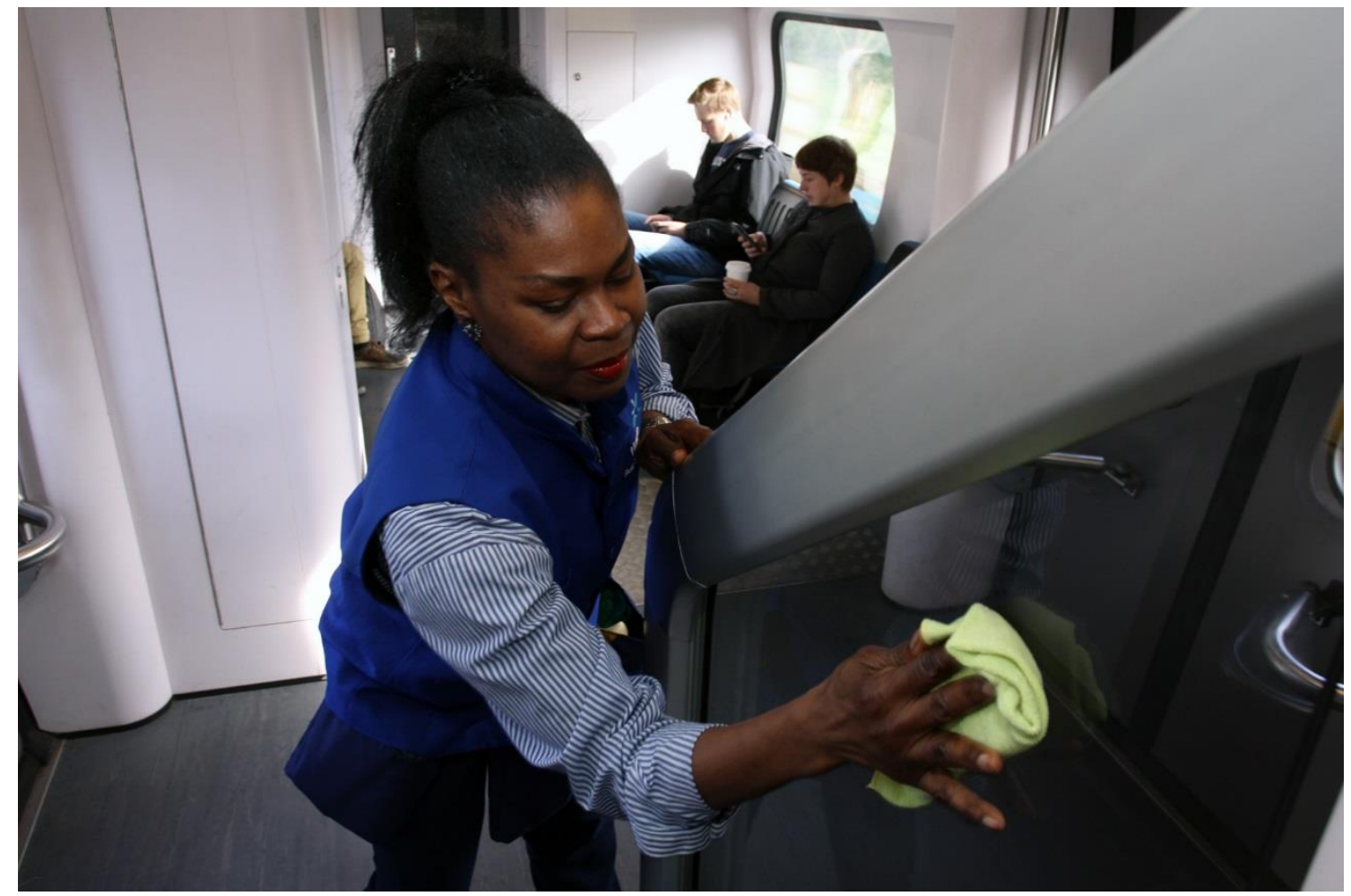

Figure 3. A cleaner who participated in the second study.

\section{Participants}

All participants (study 1,N=506; study 2, N=1,113) were travelling with Netherlands Railways and were either part of the experimental condition (study 1,N=265; study 2, $N=482$ ) or control condition (study $1, N=241$; study $2, N=631$ ). In the first study, average age was 32 years $(M=31.9, S D 16.6)$; in the second study, average age was 34 years $(M=34.4, S D=$ 16.9). See Table 1 for a full overview of demographic information. 
Table 1. Overview demographic information participants

\begin{tabular}{|l|l|l|}
\hline variables & $\%(\mathbf{N})$ study $\mathbf{1}$ & $\%(\mathbf{N})$ study 2 \\
\hline age & & \\
\hline$<24$ & $53.2(269)$ & $42.6(474)$ \\
\hline $25-49$ & $27.9(141)$ & $34.1(379)$ \\
\hline $50-64$ & $12.6(64)$ & $14.7(161)$ \\
\hline $65>$ & $6.1(31)$ & $7.5(82)$ \\
\hline missing & $.2(1)$ & $1.5(17)$ \\
\hline total & $100(506)$ & $100(1,113)$ \\
\hline & & \\
\hline gender & & \\
\hline male & $37.5(190)$ & $35.9(400)$ \\
\hline female & $62.5(316)$ & $62.6(697)$ \\
\hline missing & $0(0)$ & $1.4(16)$ \\
\hline total & $100(506)$ & $100(1,113)$ \\
\hline & & \\
\hline travel motive & & \\
\hline commuting & $22.7(115)$ & $20.4(227)$ \\
\hline business trip & $5.9(30)$ & $13.7(153)$ \\
\hline school or university & $8.7(44)$ & $26.8(298)$ \\
\hline visiting family or friends & $32.4(164)$ & $14.3(159)$ \\
\hline leisure (other than 'visiting family or friends') & $20.2(102)$ & $20.3(226)$ \\
\hline other & $10.1(51)$ & $4.1(46)$ \\
\hline missing & $0(0)$ & $.4(4)$ \\
\hline total & $100(506)$ & $100(1,113)$ \\
\hline
\end{tabular}

\section{Measures}

The survey contained 24 items (on a 10 point Likert scale) about passengers' satisfaction with the service and questions about passengers' perceptions of staff, cleanliness, comfort, trip speed, atmosphere, and cleanliness of individual interior elements. The same survey was used in both studies. We wanted to gain a deeper understanding of passengers' perception of cleanliness. Therefore, participants were asked to evaluate the cleanliness of individual interior elements (i.e., floor, seating, table, trash bin, walls, windows, and doors). In addition, background information about the passengers' gender, age, and travel motive was collected. The items about passengers' satisfaction and perception were derived from previous research in this area (Van Hagen \& Sauren, 2014). Table 2 shows the individual items and Cronbach's alpha of the constructs. Two items were emitted from the "comfort construct" (i.e., I could easily find a seat on this train, I am able to spend my time pleasantly in this train) to improve the Cronbach's alpha. Hence, all constructs were considered reliable with a Cronbach's alpha value above 0.7 (Field, 2009) as shown in Table 2. 
Table 2. Scale items and coefficient alpha reliability of study 1 and study 2

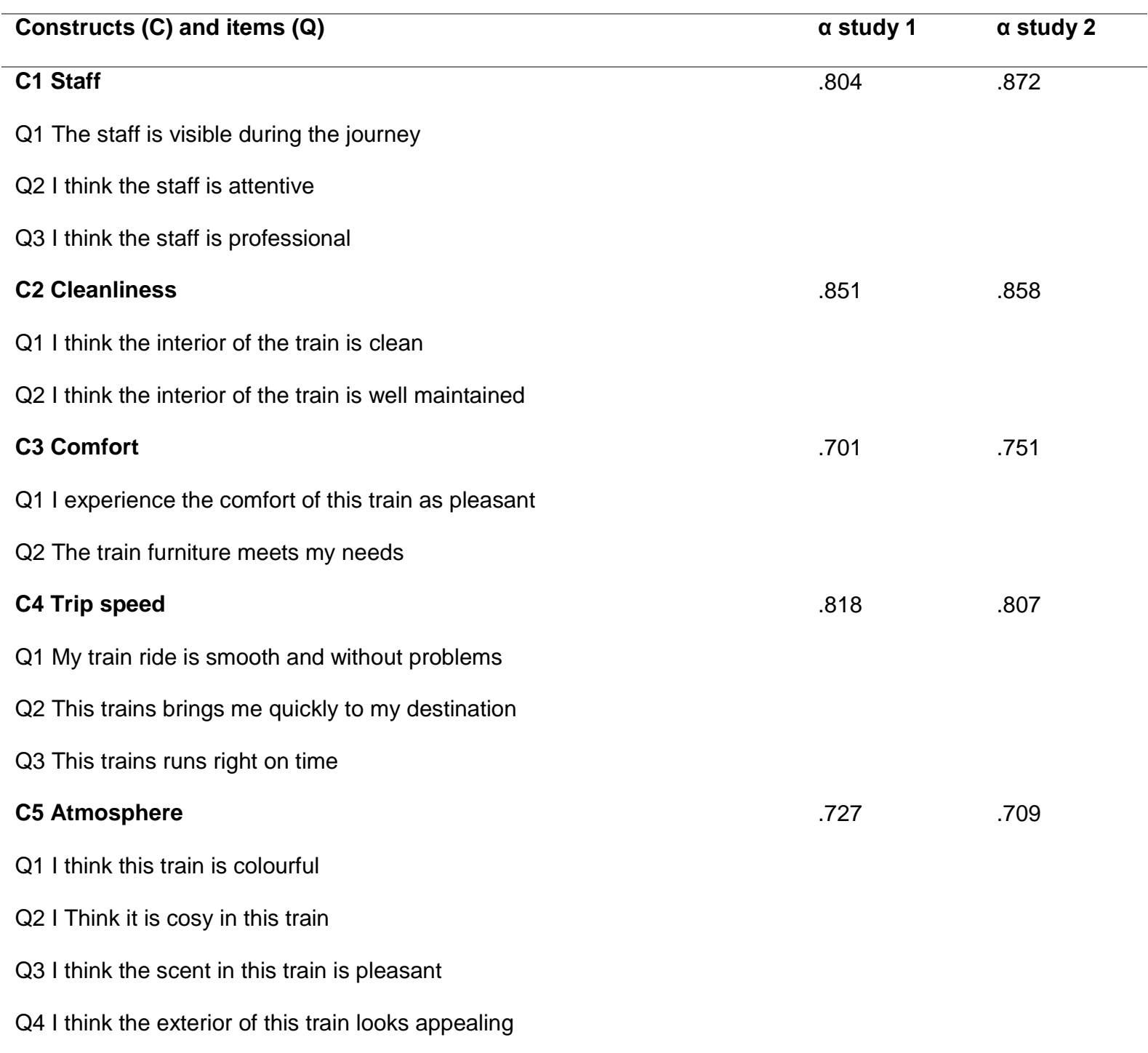

\section{Manipulation check}

To determine whether the cleaning staff was indeed perceived as more visible during the experimental condition, we conducted a manipulation check for both studies. One item of the "staff construct" (i.e., the staff is visible during the journey) was used to ascertain if the staff was perceived as more visible during the experimental condition. An analysis of variance revealed that participants in the experimental condition indeed evaluated the cleaning staff as being more visible $(M=6.1, S D=2.10)$ than the participants in the control condition $(M=5.6$, $\mathrm{SD}=2.19 ; \mathrm{F}(1,455)=6.94, \mathrm{p}=<.05)$ of the first study. Similar findings were obtained in the second study. Participants in the experimental condition evaluated the cleaning staff as being 
more visible $(M=5.6, S D=2.29)$ than the participants in the control condition $(M=4.8, S D=$ $2,38 ; F(1,1035)=32.44, p=<.001)$.

\section{Results}

Multivariate Analysis of Variance (MANOVA) was performed with the condition (experimental or control) as independent variable and all composite variables (Table 2) as dependent variables. The models for both studies appeared to be significant $(F(6,469)=2.52, p=<.05$; $F(6,1101)=11.51, p=<.001)$. The presence of cleaning staff positively influenced perceptions of staff, cleanliness, comfort, and satisfaction in the first study, the perception of trip speed and atmosphere were not significantly impacted by the presence of cleaning staff. Similar results were found in the second study. Except for trip speed, significant differences were found for all dependent variables between the control and experimental condition. No significant differences were found between male and female participants in both studies. An overview of the constructs, means for the experimental condition (EC) and control condition (CC), F values, and p-values for study 1 and study 2 are presented in Table 3. The physical presence of cleaning staff positively influenced the perception of staff, cleanliness, comfort, and the general satisfaction of passengers in both studies. The perception of atmopshere was only significant in the second study, which might be caused by the intervention (i.e., hospitality training, corporate uniform). Overall, the effects in the second study were considered to be stronger and more robust. 
Table 3. Passengers' perceptions and satisfaction in control (CC) and experimental condition (EC) (study 1 \& study 2)

\begin{tabular}{|c|c|c|c|c|c|c|c|c|}
\hline & Study 1 & & & & Study & & & \\
\hline & $\begin{array}{l}\text { EC } \\
M(S D)\end{array}$ & $\begin{array}{l}\text { CC } \\
M(S D)\end{array}$ & $\mathbf{F}$ & p & $\begin{array}{l}\text { EC } \\
M(S D)\end{array}$ & $\begin{array}{l}\text { CC } \\
M(S D)\end{array}$ & $\mathbf{F}$ & $p$ \\
\hline Staff & $\begin{array}{l}6.98 \\
(1.22)\end{array}$ & $\begin{array}{l}6.70 \\
(1.33)\end{array}$ & 5.81 & $<.05$ & $\begin{array}{l}6.45 \\
(1.47)\end{array}$ & $\begin{array}{l}5.99 \\
(1.59)\end{array}$ & 24.76 & $<.001$ \\
\hline Cleanliness & $\begin{array}{l}6.66 \\
(1.49)\end{array}$ & $\begin{array}{l}6.37 \\
(1.55)\end{array}$ & 4.29 & $<.05$ & $\begin{array}{l}6.49 \\
(1.19)\end{array}$ & $\begin{array}{l}6.16 \\
(1.25)\end{array}$ & 19.79 & $<.001$ \\
\hline Comfort & $\begin{array}{l}7.02 \\
(1.20)\end{array}$ & $\begin{array}{l}6.70 \\
(1.29)\end{array}$ & 8.60 & $<.05$ & $\begin{array}{l}7.23 \\
(1.28)\end{array}$ & $\begin{array}{l}6.70 \\
(1.51)\end{array}$ & 37.63 & $<.001$ \\
\hline Trip speed & $\begin{array}{l}7.80 \\
(1.43)\end{array}$ & $\begin{array}{l}7.81 \\
(1.41)\end{array}$ & .01 & $n s$ & $\begin{array}{l}7.69 \\
(1.76)\end{array}$ & $\begin{array}{l}7.80 \\
(1.51)\end{array}$ & 1.08 & $n s$ \\
\hline Atmosphere & $\begin{array}{l}6.56 \\
(1.06)\end{array}$ & $\begin{array}{l}6.47 \\
(1.04)\end{array}$ & .74 & $n s$ & $\begin{array}{l}6.29 \\
(1.16)\end{array}$ & $\begin{array}{l}6.13 \\
(1.16)\end{array}$ & 5.46 & $<.05$ \\
\hline Satisfaction & $\begin{array}{l}7.44 \\
(.99)\end{array}$ & $\begin{array}{l}7.25 \\
(1.06)\end{array}$ & 4.70 & $<.05$ & $\begin{array}{l}7.35 \\
(.94)\end{array}$ & $\begin{array}{l}7.09 \\
(1.06)\end{array}$ & 17.47 & $<.001$ \\
\hline
\end{tabular}

In addition, we were interested if the presence of cleaning staff affected the perceived cleanliness of individual interior elements. A similar procedure was followed. The models (MANOVA) appeared to be significant in both studies $(F(7,498)=2.37, p=<.05 ; F(7,1105)=$ 7.54, $p=<.001$ ), a detailed overview of the results can be found below (Table 4). Overall, positive effects of the presence of cleaning staff were found for cleanliness perceptions. Nonsignificant effects were found for walls (only in study 1 ) and windows. Our expectation is that passengers did not note differences since cleaners were not instructed to clean the walls and windows. In addition, cleaners were obviously not able to clean the windows from the outside during the journey.

Table 4. Passengers' perceptions of cleanliness of individual interior elements in control (CC) and experimental condition (EC) (study 1 \& study 2)

\begin{tabular}{llllllll}
\hline Study 1 & \multicolumn{7}{c}{ Study 2 } \\
\hline EC & CC & & EC & CC \\
M (SD) & M (SD) & F & p & M (SD) & M (SD) & F & p \\
\hline
\end{tabular}




\begin{tabular}{|c|c|c|c|c|c|c|c|c|}
\hline Floor & $\begin{array}{l}5.98 \\
(1.71)\end{array}$ & $\begin{array}{l}5.82 \\
(1.77)\end{array}$ & 1.09 & $n s$ & $\begin{array}{l}5.86 \\
(1.75)\end{array}$ & $\begin{array}{l}5.56 \\
(1.77)\end{array}$ & 7.84 & $<.05$ \\
\hline Seating & $\begin{array}{l}6.32 \\
(1.66)\end{array}$ & $\begin{array}{l}5.88 \\
(1.75)\end{array}$ & 8.10 & $<.05$ & $\begin{array}{l}6.22 \\
(1.61)\end{array}$ & $\begin{array}{l}5.96 \\
(1.68)\end{array}$ & 6.48 & $<.05$ \\
\hline Table & $\begin{array}{l}6.52 \\
(1.59)\end{array}$ & $\begin{array}{l}6.21 \\
(1.59)\end{array}$ & 4.60 & $<.05$ & $\begin{array}{l}6.74 \\
(1.45)\end{array}$ & $\begin{array}{l}6.25 \\
(1.63)\end{array}$ & 26.92 & $<.001$ \\
\hline Trash bin & $\begin{array}{l}5.76 \\
(2.11)\end{array}$ & $\begin{array}{l}5.19 \\
(1.93)\end{array}$ & 9.93 & $<.05$ & $\begin{array}{l}5.93 \\
(1.93)\end{array}$ & $\begin{array}{l}5.25 \\
(2.00)\end{array}$ & 31.77 & $<.001$ \\
\hline Walls & $\begin{array}{l}6.66 \\
(1.64)\end{array}$ & $\begin{array}{l}6.49 \\
(1.54)\end{array}$ & 1.48 & ns & $\begin{array}{l}6.72 \\
(1.57)\end{array}$ & $\begin{array}{l}6.38 \\
(1.61)\end{array}$ & 12.42 & $<.001$ \\
\hline Windows & $\begin{array}{l}6.22 \\
(1.68)\end{array}$ & $\begin{array}{l}6.04 \\
(1.63)\end{array}$ & 1.45 & $n s$ & $\begin{array}{l}5.81 \\
(2.01)\end{array}$ & $\begin{array}{l}5.72 \\
(1.83)\end{array}$ & 0.64 & $n s$ \\
\hline Doors & $\begin{array}{l}6.74 \\
(1.52)\end{array}$ & $\begin{array}{l}6.47 \\
(1.55)\end{array}$ & 3.87 & $<.05$ & $\begin{array}{l}6.65 \\
(1.67)\end{array}$ & $\begin{array}{l}6.28 \\
(1.69)\end{array}$ & 13.46 & $<.001$ \\
\hline
\end{tabular}

\section{Discussion}

Two experimental field studies were performed to evaluate the effect of the visible presence of cleaning staff on customer experience of train passengers. Based on the "halo effect" (Eagly et al., 1991), we expected that the physical presence of cleaning-staff would positively influence customer experience (i.e., perception of cleanliness, staff, comfort, trip speed, and atmosphere) and the general satisfaction of passengers. The "halo effect" suggests that people tend to assume that one positive trait (i.e., presence of friendly and helpful cleaning staff) implies the presence of other positive traits (e.g., comfortable seating, shorter travel time, positve perception of atmosphere). Between the two studies, cleaners received hospitality training and corporate uniforms as opposed to traditional cleaning uniforms in the first study. We expected that the training and corporate uniforms would strengthen the positive effects of the visible presence of the cleaners. This was confirmed by the findings of study 2 .

The presence of cleaners positively influenced satisfaction, perceptions of staff, cleanliness, and comfort in both studies. The perception of atmosphere was only significant in the second study, perceived trip speed was non-significant in both studies. Interestingly, differences between control and experimental condition increased and the presence of 
cleaners was significantly related to the perception of atmosphere after the intervention (i.e., hospitality training, corporate uniform). Suggesting, the training and corporate uniforms indeed strengthened the effects of the visible presence of the cleaners. When it comes to individual interior elements, we expected that the elements touched by the cleaners (regardless of the level of cleanliness) would be perceived as cleaner. It appeared that the presence and cleaning activities of the cleaning staff indeed positively influenced the perceived cleanliness of the seating, table, trash bin, and doors in both studies.

Although not the main aim of the current study, day-time cleaners indicated to feel healthier and have more fun at work since they were openly appreciated by train passengers. This finding was supported by Ueno et al. (1984), who evaluated the effect of consecutive night-time work on health conditions among cleaners of the "Bullet trains" in Japan. Gastrointestinal disorder, general fatigue, and depression was more common among cleaners working night-time hours compared to cleaners who worked during day-time. Our expectation is that day-time cleaning reduces the experience of the dirty-work stigma by cleaners, as outlined by Van Vlijmen (2017). Since cleaners are part of the primary service delivery process they feel probably more respected and valued by end-users who directly benefit from their efforts. The introduction of day-time cleaning alone will not eliminate the experience of the dirty-work stigma by cleaners. Many more measures, such as reduction of work-pressure, increase of salary, and recognition are needed to reduce the experience of the dirty-work stigma.

Moreover, FM research on cleaning or cleanliness appeared to be limited and mostly qualitative, as noted by Klungseth and Olsson (2013) and Van Vlijmen (2017). FM research seldom focusses on cleaning or the role of cleaning staff. This can be considered as peculiar in a market which employs millions of people worldwide and heavily depends on their daily efforts. This study took a first step by evaluating the effect of cleaning staff on end-user perceptions and satisfaction.

The present study is limited because of several reasons. The focus on train passengers and environment might reduce reproducibility of our findings to different settings. For most train 
passengers, a train journey typically has an obligatory character and passengers tend to be task oriented (Van Hagen et al., 2014). End-users in other service environments such as hotels or offices might be involved in other activities and pursue less task oriented goals. Moreover, multiple cleaners were employed in the two different studies. Thus, the stimulus (cleaning staff) was therefore probably not identical

\section{Conclusions and implications}

The studies demonstrated that perceptions and satisfaction of train passengers can be influenced by introducing daytime work: cleaners work during daytime making their bodies, uniforms, and work visible to customers, with possible influences on affective responses of both customers and employees. Insights were derived through two experimental field studies performed on trains of Netherlands Railways (NS). The findings of this study carry several important implications.

Future research should consider the effect of day-time cleaning on health, social wellbeing, and job satisfaction of cleaning staff. It would be interesting and relevant to determine if cleaners who work during daytime experience less stress and are more satisfied with their jobs. Moreover, it would be interesting to further unravel the concept of cleanliness by performing experimental field studies on antecedents of end-user perceptions of cleanliness (e.g., scent, use of materials).

This study carries several important implications for the FM industry. The results allow in-house and corporate facility managers to better understand the effect of their cleaning staff on end-user perceptions and satisfaction. This understanding might lead to better decision making. Instead of improving end-user perceptions of cleanliness by investing in additional cleaning services, in-house and corporate facility managers might decide to invest in different ways of cleaning. For example by focussing on individual interior elements perceived as most important by end-users. In this study, cleanliness of the seating area and table (direct surroundings) were most strongly correlated with the overall perception of cleanliness. 
Interestingly, cleaners were instructed to only clean unoccupied seats. Suggesting that effects might be even larger when occupied seats are cleaned during the journey, if desired by the customer. The personal service to the passenger will probably positively influence customer experience.

In brief, this paper provides insights into the effects of increasing the visibility of cleaning staff on perceptions and satisfaction of end-users, offering several directions for future research. In addition, we hope to encourage in-house and corporate facility managers to take their cleaning staff out of the shadows, into the light and thereby positively influence the perceptions and satisfaction of their end-users.

\section{References}

Agular, L. L. 2001. Doing Cleaning Work'scientifically': The Reorganization of Work in the Contract Building Cleaning Industry. Economic and industrial Democracy, 22, 239269.

Aronoff, J., Woike, B. A. \& Hyman, L. M. 1992. Which Are the Stimuli in Facial Displays of Anger and Happiness? Configurational Bases of Emotion Recognition. Journal of personality and social psychology, 62, 1050.

Ashforth, B. E. \& Kreiner, G. E. 1999. "How Can You Do It?": Dirty Work and the Challenge of Constructing a Positive Identity. Academy of management Review, 24, 413-434.

Baker, J. 1987. The Role of the Environment in Marketing Services: The Consumer Perspective. In J. Czepiel, C. Congram, \& J. Shanahan (Eds.), The services challenge: Integrating for competitive advantage (pp. 79-84). Chicago: American Marketing Association.

Baker, J., Grewal, D. \& Parasuraman, A. 1994. The Influence of Store Environment on Quality Inferences and Store Image. Journal of the academy of marketing science, 22, 328-339.

Baker, J., Parasuraman, A., Grewal, D. \& Voss, G. B. 2002. The Influence of Multiple Store Environment Cues on Perceived Merchandise Value and Patronage Intentions. Journal of marketing, 66, 120-141.

Bitner, M. J. 1992. Servicescapes: The Impact of Physical Surroundings on Customers and Employees. Journal of Marketing, 56, 57-71.

Bitner, M. J., Booms, B. H. \& Tetreault, M. S. 1990. The Service Encounter: Diagnosing Favorable and Unfavorable Incidents. The Journal of Marketing, 71-84.

Broeders, R., Lakens, D., Midden, C. \& Ham, J. 2011. An Embodied Cognition Approach to Litter Reduction: The Grounding of Clean in Shininess. In Presentation at the Environment 2.0: the 9th Biennial Conference on Environmental Psychology, September 26-28, 2011, Eindhoven, the Netherlands.

Bywater, L. 1990. Cleaning Costs: A Case Study Exercise. Facilities, 8, 16-18.

Da Luz Reis, A. T. \& Dias Lay, M. C. 2009. Internal and External Aesthetics of Housing Estates. Environment and Behavior, 42, 271-294.

Eagly, A. H., Ashmore, R. D., Makhijani, M. G. \& Longo, L. C. 1991. What Is Beautiful Is Good, but...: A Meta-Analytic Review of Research on the Physical Attractiveness Stereotype. Psychological bulletin, 110, 109. 
Field, A. 2009. Discovering Statistics Using Spss, Sage publications.

Gbadegesin, J. T. \& Babatunde, T. O. 2015. Investigating Experts' Opinion on Outsourcing Decision in Facilities Management Practice in Public Universities in Nigeria. Journal of Facilities Management, 13, 27-44.

Hood, J. C. 1988. From Night to Day: Timing and the Management of Custodial Work. Journal of Contemporary Ethnography, 17, 96-116.

Houston, A. \& Youngs, G. 1996. Proactive Outsourcing-a Strategic Partnership: Rank Xerox Technical Centre. Facilities, 14, 40-47.

Hui, E. C., Zhang, P.-H. \& Zheng, X. 2013. Facilities Management Service and Customer Satisfaction in Shopping Mall Sector. Facilities, 31, 194-207.

Hui, E. C. \& Zheng, X. 2010. Measuring Customer Satisfaction of Fm Service in Housing Sector: A Structural Equation Model Approach. Facilities, 28, 306-320.

Johanne Klungseth, N. 2014. Organising Cleaning in Norwegian Public Fm. Journal of Facilities Management, 12, 382-410.

Klungseth, N. J., Klungseth, N. J., Blakstad, S. H. \& Blakstad, S. H. 2016. Organising inHouse Cleaning Services in Public Fm. Facilities, 34, 828-854.

Klungseth, N. J. H. \& Olsson, N. O. E. 2013. Norwegian Cleaning Research: An Overview and Categorization. Facilities, 31, 290-313.

Lemon, K. N., \& Verhoef, P. C. (2016). Understanding customer experience throughout the customer journey. Journal of Marketing, 80(6), 69-96.

Parish, J. T., Berry, L. L. \& Lam, S. Y. 2008. The Effect of the Servicescape on Service Workers. Journal of Service Research, 10, 220-238.

Pine, B. J., \& Gilmore, J. H. (1998). Welcome to the experience economy. Harvard business review, 76, 97-105.

Schneider, B., Ehrhart, M. G., Mayer, D. M., Saltz, J. L. \& Niles-Jolly, K. 2005. Understanding Organization-Customer Links in Service Settings. Academy of Management Journal, 48, 1017-1032.

Ueno, M., Nakagiri, S., Taniguchi, T., Arisawa, T., Mino, Y., Kodera, R., Kanazawa, S., Oyama, K., Ogawa, T. \& Ohta, T. 1984. Effects of Consecutive Night-Shift Work on Health Conditions among Car-Cleaners of Super-Express Trains. Japanese Journal of Industrial Health, 26, 483-491.

Van Hagen, M., Galetzka, M. \& Pruyn, A. T. 2014. Waiting Experience in Railway Environments. Journal of Motivation, 2, 41-55.

Van Hagen, M. \& Sauren, J. 2014. Influencing the Train Experience: Using a Successful Measurement Instrument. Transportation Research Procedia, 1, 264-275.

Van Lierop, D., Badami, M. G. \& El-Geneidy, A. M. 2017. What Influences Satisfaction and Loyalty in Public Transport? A Review of the Literature. Transport Reviews, 1-21.

Van Ryzin, G. G., Immerwahr, S. \& Altman, S. 2008. Measuring Street Cleanliness: A Comparison of New York City's Scorecard and Results from a Citizen Survey. Public Administration Review, 68, 295-303.

Van Vlijmen, J. 2017. Ik Zie, Ik Zie, Wat Jij Niet Ziet. Een Publiektheologische Analyse Van De Onzichtbare Schoonmaker (I See, I See What You Do Not See. A Public Theological Analysis of the Invisible Cleaner). Ph.D. Thesis, Radboud University Nijmegen.

Verhoef, P. C., Lemon, K. N., Parasuraman, A., Roggeveen, A., Tsiros, M. \& Schlesinger, L. A. 2009. Customer Experience Creation: Determinants, Dynamics and Management Strategies. Journal of retailing, 85, 31-41.

Vilnai-Yavetz, I. \& Rafaeli, A. 2011. The Effects of a Service Provider's Messy Appearance on Customer Reactions. Services Marketing Quarterly, 32, 161-180.

Vos, M. C., Galetzka, M., Mobach, M. P., Van Hagen, M. \& Pruyn, A. T. H. in press. Cleanliness Unravelled: A Review and Integration of Literature. Journal of Facilities Management. 
Wakefield, K. L. \& Blodgett, J. G. 1996. The Effect of the Servicescape on Customers' Behavioral Intentions in Leisure Service Settings. Journal of Services Marketing, 10, 45-61.

Wells, V. K. \& Daunt, K. L. 2015. Eduscape: The Effects of Servicescapes and Emotions in Academic Learning Environments. Journal of Further and Higher Education.

Whatley, V., Jackson, L. \& Taylor, J. 2012. Improving Public Perceptions around Cleanliness and Health Care Associated Infection in Hospitals (Service Improvement). Journal of Infection Prevention, 13, 192-199.

Whitehead, H., May, D. \& Agahi, H. 2007. An Exploratory Study into the Factors That Influence Patients' Perceptions of Cleanliness in an Acute Nh's Trust Hospital. Journal of Facilities Management, 5, 275-289. 